\title{
Combination Intravenous and Intra-Articular Tranexamic Acid Compared with Intravenous Only Administration and No Therapy in Total Knee Arthroplasty: A Case Series Study
}

\author{
Buntting $C^{1}$, Sorial $R^{1}$, Coffey $S^{1}$, Eslick $G^{1}$
}

\begin{abstract}
Introduction: Excessive perioperative bleeding requiring transfusion remains a potential complication of Total Knee Arthroplasty (TKA). There is overwhelming evidence supporting the efficacy of intravenous Tranexamic acid to reduce bleeding and the need for transfusion in TKA. There is still some question regarding the efficacy of other methods of Tranexamic acid administration. This case series study evaluated the effects of the use of intravenous Tranexamic acid administered alone, or in combination with intra-articular tranexamic acid on transfusion rate and other clinical outcomes; and compared this to a group of patients who received neither treatment.

Method: We conducted a case review of 150 patients who had undergone TKA from 2012-2015. 50 patients underwent TKA with IV Tranexamic acid (Group A). A further 50 patients underwent TKA with IV Tranexamic acid in combination with intra-articular administration of 2grams of Tranexamic acid in $20 \mathrm{ml}$ saline (Group B). A final 50 patients underwent TKA without the use of Tranexamic acid (nontreatment group). Outcome measures were transfusion rate, change in haemoglobin and haematocrit, medical review events, patient mortality and changes in knee flexion and extension measurements at six weeks after surgery.
\end{abstract}

Results: There were no significant differences in red blood cell transfusion rates between the nontreatment group and the two treatment groups, however an absolute reduction in transfusion rate from $8 \%$ to $0 \%(\mathrm{p}=0.134)$ was observed. The mean change of haemoglobin level in the non-treatment group was 29 while in treatment groups $A$ and $B$, this was 23 and 19 respectively $(\mathrm{p}=0.0001)$. No significant difference was observed between treatment group A and B.

There was a significant difference in post-operative haemoglobin level, where mean haemoglobin

1 Chris Buntting, MD, Rami Sorial, MD, Simon Coffey, MD, Guy Eslick, MD Nepean Hospital, Derby St, Penrith 2750, Australia

(Direct reprint requests to Simon Coffey)

\footnotetext{
(C) 2016 Buntting, Sorial, Coffey, Eslick. All rights reserved.

Authors retain copyright and grant the journal right of first publication with the work. Reconstructive Review follows the Creative Commons Attribution-NonCommercial CC BY-NC. This license allows anyone to download works, build upon the material, and share them with others for non-commercial purposes as long as they credit the senior author, Reconstructive Review, and the Joint Implant Surgery \& Research Foundation (JISRF). An example credit would be: "Courtesy of (senior author's name), Reconstructive Review, JISRF, Chagrin Falls, Ohio".
} 
concentrations in non-treatment, Group A and B were 110 vs 115 vs 123 respectively $(\mathrm{P}=0.0001)$. Pairwise comparison showed that Group B was significantly different when compared to both non treatment $(\mathrm{p}=0.0001)$ and treatment group $A(p=0.020)$. There were no significant differences observed in other outcomes.

Conclusion: This study supports the existing literature and suggests that the use of IV Tranexamic acid alone or in combination with intra-articular dose in TKA may reduce the requirement for transfusion (Level IV evidence). Furthermore, this study suggests that the use of tranexamic acid as a combination of Intravenous and intra-articular administration has no effect on range of motion, or medical complications during hospital stay. Although it was not a statistically significant finding, our study suggested a trend towards a greater reduction in haemoglobin and haematocrit fall in the combination therapy group when compared to IV Tranexamic acid alone.

Keywords: arthroplasty, replacement, knee, tranexamic acid administration, intravenous injections, intra-articular treatment outcome range of motion, articular blood loss, surgical

Level of Evidence: AAOS Therapeutic Level IV

\section{Introduction}

Total knee arthroplasty (TKA) is a commonly performed orthopaedic procedure which provides significant pain relief and improves the quality of life of patients suffering arthritic disorders of the knee. In 2013 over 51000 primary knee replacements were undertaken in Australia, a figure testament to the efficacy and demand for this procedure [1]. Excessive perioperative bleeding remains a potential complication of TKA in which blood loss ranges from $500 \mathrm{ml}$ to $1.5 \mathrm{~L}$ [2-7]. Furthermore, true blood losses may be underestimated as often hidden blood losses are not taken into account [6,7]. Regardless, a reduction in haemoglobin concentration by $20-50 \mathrm{~g} / \mathrm{L}$ has been observed following TKA [5-8]. This may lead to post-operative anaemia with prevalence rates estimated to be approximately $51 \%$ in patients who have undergone TKA [9].

Post-operative anaemia has been associated with morbid outcomes including increases in the length of hospital stay, poorer post-operative physical function, an increase in infection rates and increased rates of readmission $[9,10]$. However, there exists conflicting evidence surrounding the effects of post-operative anaemia in patients who have TKA. Some studies suggest that there is no effect on physical function, quality of life and morbidity between anaemic and non-anaemic patients who have undergone TKA [10-14].
Red blood cell transfusion is often implemented to treat anaemia and the rate of red blood cell transfusion in TKA has been reported to be as high as 10-69\% [9,15]. Patients who receive a transfusion are exposed to many well documented risks. These include the risk of inoculation with blood borne pathogens, the risk of venous and arterial thromboses, and a number of immune mediated disorders [16]. Furthermore, it is unclear whether treatment of established anaemia in the post-operative period is beneficial; and strategies have been aimed at reducing the incidence of post-operative anaemia rather than its treatment.

A number of factors contribute to blood loss and the development of post-operative anaemia. These include the vascular nature of the knee joint and unavoidable trauma due to dissection, tissue release and bone cuts $[5,17]$. Furthermore, alterations in haemostasis also occur. Specifically, a hyperfibrinolytic state is induced through the excessive release of tissue plasminogen activator which activates plasmin resulting in the cleavage of fibrin clots, and excessive bleeding [18,19]. Additionally, alterations in iron metabolism and erythropoiesis occur in response to the inflammatory cytokines released after surgery resulting in reduced haematopoiesis [20]. Further factors such as the use of tourniquet, incision type and type drainage systems used have also been implicated in causing excessive blood loss.

A number of strategies have been developed to reduce blood loss and the requirement for red blood cell transfusion in TKA. These include deliberate hypotension, regional anaesthetic techniques, variation in incision approaches and the use or absence of drain systems. The administration of erythropoietin stimulating agents and iron supplementation has also been trialled with varying results [2135]. One intervention which has been demonstrated to significantly reduce blood loss in TKA and the requirement for transfusion is the use of intravenous Tranexamic acid.

The antifibrinolytic Tranexamic acid is a synthetic analogue of the amino acid lysine. Its effects on blood loss have been extensively studied and its safety is well established in many medical specialties [36]. Tranexamic acid is thought to exert its effect by competitively binding and inhibiting the lysine residues of plasminogen molecules, rendering them unable to be converted to plasmin by tissue plasminogen activator (TPa). At high doses it is thought that Tranexamic acid directly inhibits the activity of plasmin, therefore further decreasing the fibrinolytic properties of plasmin. Overall an anti-fibrinolytic phase is induced which reduces overall blood loss.

Several large studies and meta-analyses have demonstrated a reduction in blood loss and requirement for transfusion with the use of intravenous tranexamic acid [36- 
38]. In their comprehensive meta-analysis, Yang et al [34] found a significant reduction in the rate of transfusion $(\mathrm{OR}$, 0.16 [95\% CI, 0.10 to 0.25$] ; \mathrm{p}<0.0001)$. Similarly, in their meta-analysis Tan et al [38] found a reduction in transfusion rate (RR, 0.39 [95\% CI, 0.25-0.61]; P < 0.0001). Neither study demonstrated an increase in venous thromboembolic events nor other complications related to intravenous Tranexamic acid administration.

Thus there is overwhelming evidence supporting the use of intravenous Tranexamic acid in total knee arthroplasty. A number of studies have also evaluated the effects tranexamic acid when administered intra-articularly and have demonstrated similar reductions in blood loss and haemoglobin fall [39-41]. However, there is a limited database examining the clinical effects when the combination of intravenous and intra-articular tranexamic acid is used in Total Knee Arthroplasty [42]. The present study aimed to evaluate whether the combination of the use of intravenous Tranexamic acid in combination with intra-articular administration reduced transfusion rates and the change in haemoglobin and haematocrit levels on the first day after surgery. This study also evaluated the effect of this combination on the frequency of medical review events, patient mortality, and changes in knee range of motion at six weeks after surgery.

Our hypothesis was that the use of intravenous Tranexamic acid with or without Intra-articular administration would reduce any transfusion requirements; that the change in haemoglobin and haematocrit fall observed would be reduced; and that there would be no significant difference in flexion and extension measurements at six weeks as compared to the non-treatment group; and finally that there would be no difference in outcomes between Intravenous Tranexamic Acid administration and combination administration.

\section{Method}

\section{Study Design}

We designed and conducted a case series study of patients who had undergone total knee arthroplasty (TKA) and had received intravenous tranexamic acid alone or in combination with an intra-articular dose of Tranexamic acid. Our study was approved by the Nepean Blue Mountains Local Health District Human Research Ethics Committee.

\section{Patient Selection}

A sample of patient's records was drawn from the practices of two surgeons (Surgeon A and Surgeon B) and data was collected and patients organized into three groups. One group studied consisted of patients who had undergone TKA in 2012 and had not received intravenous Tranexamic acid (non-treatment group). The other group studied consisted of patients who had undergone TKA in 2014 and 2015 and had received intravenous Tranexamic acid only (treatment group A). The third group of patients was composed of patients who had undergone TKA in 2015 and had received a combination of intravenous tranexamic acid and an intra-articular dose of tranexamic acid (treatment group B).

In both treatment groups of the study we required that three total doses of IV Tranexamic acid were administered to patients. The first dose occurred in the intraoperative period and two further doses in the postoperative period with the second dose administered eight hours after surgery, and the third eight hours after the second dose. The dose of Tranexamic acid varied depending on the protocol used by the anaesthetist at surgery. Some patients were administered a $10 \mathrm{mg} / \mathrm{kg}$ dose while others were administered a standard $1 \mathrm{~g}$ dose delivered as a bolus. In treatment group $\mathrm{B}$, it was required that the dose of intra-articular tranexamic acid administered was $2 \mathrm{~g}$ in $20 \mathrm{ml}$ saline, which was left for 5 minutes before being removed via suction. Patients in the non-treatment group were included in the study if they had not received Tranexamic acid in any form.

Patients were universally excluded from the study if they were undergoing revision TKA surgery; and if they had received an iron infusion, haematopoietic colony stimulating factor or blood product transfusion prior to surgery. Patients that suffered from chronic renal failure, chronic anaemia, haemophilia, thrombophilia, other coagulation disorders or current cancer were also excluded from the study.

\section{Outcomes}

The primary study outcomes were defined as red blood cell transfusion rate in the post-operative period, and haemoglobin and haematocrit changes. Secondary outcomes included post-operative medical review events, measures of knee flexion and extension prior to surgery and six weeks after surgery, and mortality at six weeks after surgery.

Red blood cell transfusion rate was defined as the sum of the units of red blood cells transfused per patient group divided by the sum of patients in that group. Changes in haemoglobin and haematocrit levels were measured as the difference between the pre-operative and post-operative values the day after surgery. This time frame was chosen because of the short half-life of Tranexamic acid (3 hours). Haemoglobin and haematocrit values were chosen to assess blood loss because of likely error in visual assessment 
and the association of haemoglobin levels with morbidity and mortality [6,7].

Medical complications were defined as local infection, sepsis, venous thromboembolic disease, myocardial infarction, stroke, or other. Where a medical complication was of the 'other' category the details of the diagnosis were recorded. Intravenous fluid requirements were defined as the total volume of fluids other than blood products which were ordered by a doctor in the post-operative period up to discharge.

Knee flexion and extension measurements prior to surgery and six weeks after surgery were extracted from clinical notes. These measurements were made by Surgeon A or $\mathrm{B}$ without the use of general anaesthesia. Finally, mortality data was defined as death within the post-operative period to the date of follow up at six weeks.

Patient demographic and clinical characteristics were defined as patient gender, age at surgery, comorbidities, patient weight, and indication for surgery, and side that TKA was performed. Details concerning the dose of intravenous Tranexamic acid and tourniquet application time, were found in operative notes and patient medical records.

A structured data extraction tool was created and use to collect and organise data from patients' medical records. The items of the data extraction tool elicited data concerning inclusion and exclusion criteria, primary and secondary outcomes, patient demographic information and clinical characteristics. The data collected was then entered and stored on an Excel spreadsheet. A single researcher collected and stored this data.

\section{Statistical Analysis}

All statistical analysis was performed using SPSS v.22.0 (IBM Corp., Armonk, NY, USA). Propensity score matching was employed in our study to match for patient characteristics. This method was implemented to reduce bias inherent in retrospective studies [47]. The covariates controlled for were age at surgery, gender, pre-operative haemoglobin concentration and pre-operative haematocrit. Match tolerance was set at 0.1 .

The Kruskal-Wallis H Test was used to analyse for any significant difference amongst the three groups of patients, and where significance was found, a pairwise comparison of means was conducted to compare the means of the outcomes in the treatment and non-treatment group. This technique was used to compare baseline characteristics of the treatment and non-treatment groups. These statistical techniques were used as it was assumed that there was not a normal distribution of values due to the small sample size. All P-values calculated were two-tailed; and the alpha level of significance was set at 0.05 . Patient demographic and clinical characteristics were reported as mean and standard deviation or confidence interval for numeric-scaled features and percentages for discrete characteristics.

\section{Results}

A total of 282 patients were studied from the records of the authors and medical records. This consisted of 128 patients who had not received intravenous Tranexamic acid, and a further 92 patients who had received Tranexamic acid, and a further 62 patients who had received a combination of intravenous tranexamic acid and intra-articular tranexamic acid. The entire medical record for each patient was investigated and data extracted using the data extraction tool. Inclusion and exclusion criteria were then applied resulting in a total of 50 patients in treatment group A, 57 patients in treatment group B, and 81 patients in the non-treatment arm. The non-treatment group $(n=81)$ and treatment group B were then matched with the treatment group $A(n=50)$. This resulted in a complete match and 50 patients per group.

\section{Baseline Characteristics}

There were no significant differences in baseline characteristics between the treatment group and the non-treatment group. Baseline characteristics of both treatment groups and non-treatment groups are listed in table 1. In all arms there were a larger proportion of female patients $(64 \%, 68 \%$ and $56 \%, \mathrm{p}=0.412)$ and the majority of patients suffered from osteoarthritis.

\section{Surgical Characteristics}

The surgical care of patients included in the studied differed only in the interventions that were studied (Table 2). In the non-treatment arm, the average length that the tourniquet was kept inflated was 54 minutes (20 S.D.) while in Treatment Group B this was 13 minutes (15 S.D.). The average dose of Tranexamic acid administered in three doses to treatment group A and B was $1.1 \mathrm{~g}(0.2$ S.D.) and $0.9 \mathrm{~g}$ (0.1 S.D.) respectively. There was no significant difference between groups in terms of the use of drains and the proportion of patients that required patellar resurfacing.

\section{Primary Outcomes}

The primary outcomes are listed in Table 3 . There were no significant differences in red blood cell transfusion rates between the non-treatment group and either of the treatment groups ( 4 vs 0 vs $0, p=0.134$ ), however no patients in the treatment groups required transfusion. There was a significant difference in post-operative haemoglobin level, 
Table 1: Demographic and Clinical Characteristics of Patients

\begin{tabular}{|c|c|c|c|c|}
\hline & No Treatment & $\begin{array}{l}\text { IV Tranexamic } \\
\text { Acid }\end{array}$ & $\begin{array}{l}\text { Combination IV and } \\
\text { IA Tranexamic Acid }\end{array}$ & P-Value \\
\hline Sample Size & 50 & 50 & 50 & \\
\hline Mean Age (years) & 65 (8.4 S.D.) & 66 (9.1 S.D.) & 68 (7.6 S.D.) & 0.101 \\
\hline $\begin{array}{l}\text { Gender: } \\
\text { - Female } \\
\text { - Male }\end{array}$ & $\begin{array}{l}32(64 \%) \\
18(36 \%)\end{array}$ & $\begin{array}{l}34(68 \%) \\
16(32 \%)\end{array}$ & $\begin{array}{l}28(56 \%) \\
22(44 \%)\end{array}$ & 0.412 \\
\hline Patient Weight $(\mathrm{kg})$ & 89.4 (19.3 S.D.) & 92.9 (20.7 S.D.) & 89.3 (7.6 S.D.) & 0.667 \\
\hline $\begin{array}{l}\text { Indication: } \\
\text { - Osteoarthritis } \\
\text { - Rheumatoid } \\
\text { Arthritis } \\
\text { - Other or } \\
\text { Unspecified }\end{array}$ & $50(100 \%)$ & $\begin{array}{l}47(94 \%) \\
2(4 \%) \\
1(2 \%)\end{array}$ & $50(100 \%)$ & 1.00 \\
\hline $\begin{array}{l}\text { Pre-Operative } \\
\text { Haemoglobin }\end{array}$ & 139 (13.1 S.D.) & 138 (10.6 S.D.) & 142 (12.7 S.D.) & 0.224 \\
\hline $\begin{array}{l}\text { Pre-Operative } \\
\text { Haematocrit }\end{array}$ & 0.42 (0.03 S.D.) & 0.42 (0.03 S.D.) & 0.43 (0.04 S.D.) & 0.037 \\
\hline
\end{tabular}

Table 2: Surgical Characteristics of Non-Treatment and Treatment Groups

\begin{tabular}{|l|l|l|l|l|}
\hline & No Treatment & $\begin{array}{l}\text { IV Tranexamic } \\
\text { Acid }\end{array}$ & $\begin{array}{l}\text { Combination IV and } \\
\text { IA Tranexamic Acid }\end{array}$ & P-Value \\
\hline $\begin{array}{l}\text { Mean Dose of IV } \\
\text { TXA }\end{array}$ & 0 & $1.1(0.2$ S.D. $)$ & $0.9(0.1$ S.D. $)$ & 0.001 \\
\hline $\begin{array}{l}\text { Mean Tourniquet } \\
\text { Time }\end{array}$ & $54(20$ S.D.) & 0 & $13(15$ S.D. $)$ & 0.001 \\
\hline $\begin{array}{l}\text { Side of Operation } \\
\text { - Left } \\
\text { - Right }\end{array}$ & $\begin{array}{l}23(46 \%) \\
27(54 \%)\end{array}$ & $\begin{array}{l}34(68 \%) \\
16(32 \%)\end{array}$ & $\begin{array}{l}19(38 \%) \\
31(62 \%)\end{array}$ & 0.427 \\
\hline $\begin{array}{l}\text { Average number of } \\
\text { drains }\end{array}$ & $2(0.7$ S.D.) & $2(0.8$ S.D.) & $2(0.8$ S.D.) & 0.101 \\
\hline
\end{tabular}

Table 3: The transfusion rate and haemoglobin and haematocrit change observed after Total Knee Arthroplasty

\begin{tabular}{|c|c|c|c|c|}
\hline & No Treatment & $\begin{array}{l}\text { IV Tranexamic } \\
\text { Acid }\end{array}$ & $\begin{array}{l}\text { Combination IV and } \\
\text { IA Tranexamic Acid }\end{array}$ & P-Value \\
\hline $\begin{array}{l}\text { RBC Transfusion } \\
\text { - Total } \\
\text { - Mean }\end{array}$ & $\begin{array}{l}4 \\
0.08(8 \%)\end{array}$ & $\begin{array}{l}0 \\
0(0 \%)\end{array}$ & $\begin{array}{l}0 \\
0(0 \%)\end{array}$ & 0.134 \\
\hline $\begin{array}{l}\text { Mean Post- } \\
\text { Operative } \\
\text { Haemoglobin }(\mathrm{g} / \mathrm{L})\end{array}$ & 110 (11.7 S.D.) & 115 (12.4 S.D.) & 123 (16.3 S.D.) & 0.0001 \\
\hline $\begin{array}{l}\text { Mean Change in } \\
\text { Haemoglobin }(\mathrm{g} / \mathrm{L})\end{array}$ & 29 (7.2 S.D.) & 23 (6.8 S.D.) & 19 (13.9 S.D.) & 0.0001 \\
\hline $\begin{array}{l}\text { Mean Post- } \\
\text { Operative } \\
\text { Haematocrit }\end{array}$ & 0.34 (0.03 S.D.) & 0.35 (0.04 S.D.) & 0.37 (0.03 S.D.) & 0.0001 \\
\hline $\begin{array}{l}\text { Mean Change in } \\
\text { Haematocrit }\end{array}$ & 0.08 (0.2 S.D.) & 0.07 (0.02 S.D.) & 0.06 (0.03 S.D.) & 0.0001 \\
\hline
\end{tabular}

where mean haemoglobin concentrations in non-treatment and treatment groups $\mathrm{A}$ and $\mathrm{B}$ were 110 vs 115 vs 123 respectively $(\mathrm{P}=0.0001)$. Pairwise comparison showed that combination therapy was significantly different when compared to both non treatment $(\mathrm{p}=0.0001)$ and treatment group $\mathrm{A}(\mathrm{p}=0.020)$.

The mean change of haemoglobin levels in the no treatment group was 29 while in treatment groups A and $\mathrm{B}$, this was 23 and 19 respectively $(\mathrm{p}=0.0001)$. However, there was no significant difference observed between treatment groups. There was also a significant difference in the change in haematocrit between non-treatment group and Treatment Group A and B ( 0.08 vs 0.07 vs 0.06 , $\mathrm{p}=0.0001$ ), with pairwise comparisons showing a difference in Treatment Group A and No Treatment ( $\mathrm{p}=0.032$ ), and Treatment Group B and No Treatment $(p=0.0001)$. Again no significant difference was observed between the two treatment groups.

\section{Secondary Outcomes}

The secondary outcomes are listed in table 4. No deaths occurred during the admission period and follow up period of this study. There was an absolute difference in medical review events between the non-treatment group and treatment group $\mathrm{A}$ and $\mathrm{B}$ respectively (6 vs 12 vs $10, p=0.295$ ), however no medical review events matched the known adverse effect profile of tranexamic acid. Mean flexion and extension measurements were similar at six weeks post-operatively in all groups.

\section{Discussion}

We conducted a case series study with the primary aim of evaluating the effects of the use of the combination of intra-articular and intrave- 
Table 4: Mortality, total fluid requirements, medical review and range of motion data after total knee arthroplasty.

\begin{tabular}{|l|l|l|l|l|}
\hline & No Treatment & $\begin{array}{l}\text { IV Tranexamic } \\
\text { Acid }\end{array}$ & $\begin{array}{l}\text { Combination IV and } \\
\text { IA Tranexamic Acid }\end{array}$ & P-Value \\
\hline Death & 0 & 0 & 0 & \\
\hline $\begin{array}{l}\text { Medical Review } \\
\text { Events } \\
- \text { Sum } \\
- \text { Mean }\end{array}$ & 6 & 12 & 10 & 0.295 \\
\hline $\begin{array}{l}\text { Mean Post- } \\
\text { Operative Range of } \\
\text { Flexion (degrees) }\end{array}$ & $108(11.8$ S.D.) & $105(15.5$ S.D.) & $108(18.9$ S.D.) & 0.284 \\
\hline $\begin{array}{l}\text { Mean Post- } \\
\text { Operative Range of } \\
\text { Extension (degrees) }\end{array}$ & 3 (5.0 S.D.) & 2(4.1 S.D.) & 2(4.2 S.D.) & 0.498 \\
\hline
\end{tabular}

nous tranexamic acid in TKA, and compared this to the use of intravenous Tranexamic acid alone and a non-treatment group. Outcomes measured included the transfusion rate, change in haemoglobin level and change in haematocrit level. We also evaluated whether a difference in final extension and flexion measurements was observed at six weeks; and whether there was a difference in the sum of events that required medical review.

Our study demonstrated a reduction in transfusion rate with the use of both methods of tranexamic acid administration, and a reduction in haemoglobin and haematocrit fall in patients treated with intravenous Tranexamic acid and combination treatment when compared to no treatment. A significant difference was observed between combination therapy and IV Tranexamic acid alone where final haemoglobin levels were concerned but not in the change in haemoglobin levels, which may reflect differences in pre-operative haemoglobin levels and the cumulative effect of the difference in the change in haemoglobin.

A reduction in transfusion rate from $8 \%$ in the non-treatment group to $0 \%$ in both treatment groups $(p=0.134)$ was observed. The mean reduction in haemoglobin level was $23 \mathrm{~g} / \mathrm{L}$ in treatment group $\mathrm{A}$ and $19 \mathrm{~g} / \mathrm{L}$ in treatment group $\mathrm{B}$, as compared to $29 \mathrm{~g} / \mathrm{L}(\mathrm{p}=<0.0001$ in the non-treatment group); Pairwise analysis revealed a significant difference between Treatment Group A and no treatment $(\mathrm{p}=0.003)$ and Treatment Group B and no treatment $(\mathrm{p}=0.0001)$.

There was also a significant difference in the change in haematocrit between non-treatment group and Treatment Group A and B (0.08 vs 0.07 vs 0.06, p=0.0001), with pairwise comparisons showing a difference in Treatment Group A and No Treatment $(\mathrm{p}=0.032)$, and Treatment Group B and No Treatment ( $\mathrm{p}=0.0001)$. These results are expected and are consistent with existing knowledge concerning the use of Tranexamic acid in total knee arthro- plasty. Despite not being a statistically significant finding, our study suggested a trend towards a smaller haemoglobin and haematocrit loss in treatment group B (topical and IV) when compared to group A (IV alone).

There were no differences in mortality between groups. Furthermore, we found that the number of medical review events was not significantly different between the three groups and there were no events which matched the known adverse profile of Tranexamic acid in total knee arthroplasty. This was an expected result due to the design of our study, and the exclusion and inclusion criteria employed. This study selected for patients with limited comorbidities and patients who had a contraindication to receiving Tranexamic acid were excluded. Furthermore, mortality in TKA is very rare [46]. Our study reaffirms previous multiple meta-analyses which suggest that Tranexamic acid is a safe pharmacotherapeutic.

The use of combination therapy, intravenous tranexamic acid alone or no tranexamic acid appeared to have no effect on the range of motion achieved at six weeks when intravenous Tranexamic acid was used in TKA. The absolute mean post-operative flexion in non-treatment and treatment group A and B was 108 vs 105 vs 108 degrees respectively $(\mathrm{p}=0.284)$. Mean post-operative extension measurements also did not differ significantly between non-treatment and treatment group A and B (3 vs 2 vs 2 , $\mathrm{p}=0.498)$ The mean post-operative flexion achieved at 6 weeks in both groups supports existing literature which suggests that patients can expect an improvement in flexion of $95-110$ degrees $[43,44]$.

The significance of our findings regarding range of motion suggest that there is no evidence of stiffness being induced by the use of tranexamic acid when applied topically, intravenously or both. Similarly, higher blood loss does not seem to have resulted in stiffer knees. It is likely that other factors have a greater influence on range of motion outcomes than the application of tranexamic acid in intravenous or intra-articular forms $[43,44]$.

There are several limitations to our study. Firstly, the study design was a case series which implies the potential for confounding variables to influence the outcome. The retrospective nature of the control group in the study is an additional limitation. Finally, surgeon performance characteristics were not measured and these may have also changed over the period of time of the study. To accommo- 
date for these limitations, a minimum sample size was calculated to measure the primary outcome of our study. Furthermore, propensity score matching was used to reduce the impact of the retrospective nature of the control group on the study.

\section{Conclusion}

Our study has confirmed the findings of previous studies that have attempted to measure the effects of Tranexamic acid in total knee arthroplasty. We found an absolute reduction in transfusion rates between groups and a significant reduction in the fall in haemoglobin and haematocrit, without any changes in short term outcomes between our study groups when tranexamic acid was used. The use of Tranexamic acid serves as a safe method of reducing transfusion requirements in patients undergoing total knee arthroplasty regardless of whether it is used alone intravenously or in combination with an intra-articular administration; although our study does suggest a slightly less haemoglobin reduction when intra-articular administration is combined with intravenous administration. We suggest that future research be directed at studying feasible, cost effective regimes aimed at reducing transfusion requirements which may incorporate other interventions such as transfusion protocol changes in addition to the use of Tranexamic acid.

\section{Disclosure}

The authors declare that there is no conflict of interest regarding the publication of this paper. For full disclosures refer to last page of this journal.

\section{References}

1. Australian Orthopaedic Association National Joint Replacement Registry (2014). Lay Summary2014 Annual Report Hip and Knee Replacement. Retrieved from: https://aoanjrr.dmac.adelaide.edu.au/documents/10180/172288/Lay\%20Summary\%202014\%20Annual\%20Report\%20Hip\%20and\%20Knee\%20Replacement.

2. Callaghan J.J., O'Rourke, M.R., \& Liu, S.S. (2005) Blood management: issues and options. The Journal of Arthroplasty. 20(4), Supplementary 2, 51-4.

3. Keating, E.M., Meding, J.B., Faris, P.M., \& Ritter, M.A. (1998). Predictors of transfusion risk in elective knee surgery. Clinical Orthopaedics and Related Research. 357, 50-59.

4. Bierbaum, B.E., Calaghan, J.J., Galante, J.O., Rubash, H.E., Tooms, R.E., \& Welch RB. An analysis of blood management in patients having a total hip or knee arthroplasty. Journal of Bone and Joint Surgery. 81(1), 2-10.

5. Page, M.H., Shepherd, B.D., \& Harrison, J.M. (1984) Reduction of blood loss in knee arthroplasty. Australia New Zealand Journal of Surgery. 54(2), 141-144.

6. Sehat, K.R., Evans, R., \& Newman, J.H. (2003). How much blood is really lost in total knee arthroplasty?. Correct blood loss management should take hidden loss into account. The Knee. 7(3), 151-155.

7. Sehat, K.R., Evans, R.L., \& Newman, J.H. (2004). Hidden blood loss following hip and knee arthroplasty. Correct management of blood loss should take hidden loss into account. Journal of Bone and Joint Surgery. 86(4), 561-565.

8. Kumar, S.G., Von Arx, O.A., \& Pozo, J.L. (2005). Rate of blood loss over 4bid8 hours following total knee replacement. The Knee. 12(4), 307-309.
9. Spahn, D.R. (2010). Anemia and Patient Blood Management in Hip and Knee Surgery: A Systematic Review of the Literature. Anesthesiology, 113(2), 482-495.

10. Wang, X., Rintala, D.H., Garber, S.L., \& Henson, H. (2005). Association of hemoglobin levels, acute hemoglobin decrease, age, and co-morbidities with rehabilitation outcomes after total knee replacement. American Journal of Physical Medicine \& Rehabilitation. 84(6), 451-456.

11. Cavenaghi, F., Cerri, C., \& Panella L. (2009) Association of hemoglobin levels, acute hemoglobin decrease and age with Rehabilitation outcomes after total hip and knee replacement. European Journal of Physical and Rehabilitation Medicine. 45(3), 319-325.

12. So-Osman, C., Nelissen, R., Brand, R., Brand, A., \& Stiggelbout, A.M. (2011). Postoperative anemia after joint replacement surgery is not related to quality of life during the first two weeks postoperatively. Transfusion. 51(1), 71-81.

13. Vuille-Lessard, E., Boudreault, D., Girard, F., Ruel, M., Chagnon, M., \& Hardy, J.F. (2012). Postoperative anemia does not impede functional outcome and quality of life early after hip and knee arthroplasties. Transfusion. 52(2), 261-270.

14. Hoogeboom, T.J., van Meeteren, N.L.U., Schank, K., Kim, R.H., Miner, T., \& Stevens-Lapsley, J.E. (2015). Risk Factors for Delayed Inpatient Functional Recovery after Total Knee Arthroplasty. Biomed Research International. 2015, 1-5.

15. Bidolegui, F., Arce, G., Lugones, A., Periera, S., \& Vindver, G. (2014). Tranexamic Acid Reduces Blood Loss and Transfusion in Patients Undergoing Total Knee Arthroplasty without Tourniquet: A Prospective Randomized Controlled Trial. Open Orthopaedics Journal. 8, 250-254.

16. Vamvakas, E.C., \& Blajchman, M.A. (2009). Transfusion-related mortality: the ongoing risks of allogeneic blood transfusion and the available strategies for their prevention. Blood. 113(15), 3406-3417.

17. Sinnatamby, C. (2011). Last's Anatomy: Regional and Applied 12ed. Churchill Livingston; Sydney.

18. Pallister C.J, \& Watson, M.S. (2010). Haematology 2nd ed. Scion Publishing; Banbury,

19. Blanie, A., Bellamy, L., Rhayem, Y., Flaujac, C., Samama, C.M., Fontenay, M., \& Rosencher, N. (2013) Duration of Postoperative Fibrinolysis after Total Hip or Knee Replacement: A Laboratory Follow-up Study. Thrombosis Research.131, e6-e11.

20. Singh, S., Gudzenko, V., \& Fink, M.P. (2012) Pathophysiology of perioperative anaemia. Best Practice \& Research Clinical Anaesthesiology. 26, 431-439.

21. Zhang, Q., Guo, W., Zhang, Q., Liu, Z., Cheng, L., \& Li, Z. (2011) Comparison Between Closed Suction Drainage and Nondrainage in Total Knee Arthroplasty A Meta-Analysis. The Journal of Arthroplasty. 26(8), 1265-1272.

22. Huang, Z.Y., Jun Ma, J., Pei, F., Yang, J., Zhou, Z. Kang, P., Shen, B. (2013). Meta-analysis of Temporary Versus No Clamping in TKA. Orthopedics. 36(7), 543-550.

23. Li, T., Zhuang, Q., Weng, X., Zhou, L., \& Bian, Y. (2014). Non-continuous versus continuous wound drainage after total knee arthroplasty: a meta-analysis. International Orthopaedics. 38, 361-371.

24. Wakankar, H.M., Nicholl, J.E., Koka, R., D’Arcy, J.C. (1999). The tourniquet in total knee arthroplasty: A Prospective, randomised study. The Journal of Bone and Joint Surgery. 81-B(1), 30-33.

25. Alsaleh, K., Alotaibi, G.S., Almodaimegh, H.S., Aleem, A.A., \& Kouroukis, T. (2013). The Use of Preoperative Erythropoiesis-Stimulating Agents (ESAs) in Patients Who Underwent Knee or Hip Arthroplasty A Meta-Analysis of Randomized Clinical Trials. The Journal of Arthroplasty. 28, 1463-1472.

26. Yang, T.Q., Geng, X.L., Ding, M.C., Yang, M.X., \& Zhang, Q. (2014). The efficacy of fibrin sealant in knee surgery: A meta-analysis. Orthopaedics \& Traumatology: Surgery \& Research. 101, 331-339.

27. Sutton, P.M., Cresswell, T., Livesey, J.P., Speed, K., \& Bagga, T. (2004). Treatment of anaemia after joint replacement: A double-blind, randomised, controlled trial of ferrous sulphate versus placebo. The Journal of Bone and Joint Surgery. 86-B(1), 31-33.

28. Liu, Z. \& Yang, H. (2011). Comparison of the Minimally Invasive and Standard Medial Parapatellar Approaches for Total Knee Arthroplasty: Systematic Review and Meta-analysis. The Journal of International Medical Research. 39, 1607 1617.

29. Teng, Y., Du, W., Jin, J., Gao, X., Pan, S., Wang, J. An, L., Ma, J., \& Xia, Y. (2012). Subvastus Versus Medial Parapatellar Approach in Total Knee Arthroplasty: Metaanalysis. Orthopedics. 35(12), e1722-e1731.

30. Xu, S., Lin, X, Tong, X., \& Wang, X. (2014). Minimally Invasive Midvastus versus Standard Parapatellar Approach in Total Knee Arthroplasty: A Meta-Analysis of Randomized Controlled Trials. PLoS One. 9(5), e95311.

31. Voleti, P.B., Hamula, M.J., Baldwin, K.D., \& Lee, G. (2014).Current Data Do Not Support Routine Use of Patient-Specific Instrumentation in Total Knee Arthroplasty. The Journal of Arthroplasty. 29, 1709-1712. 
32. Xie, C., Kai Liu, K., Luxin Xiao, L., \& Tang, R. (2012). Clinical Outcomes After Computer-assisted Versus Conventional Total Knee Arthroplasty. Orthopedics. 35(5), e647-e653.

33. Paul, E.D., Ling, E., Lalonde, C., \& Thabane, L. (2007). Deliberate hypotension in orthopedic surgery reduces blood loss and transfusion requirements: a metaanalysis of randomized controlled trials. Canadian Journal of Anaesthesia. 54(10), 799-810.

34. Adie, S., Naylor, J.M., \& Harris, I.A. (2010). Cryotherapy After Total Knee Arthroplasty A Systematic Review and Meta-Analysis of Randomized Controlled Trials. The Journal of Arthoplasty. 25(5), 709-715.

35. Macfarlane, A.J.R., Prasad, G.A., Chan, V.W.S., \& Brull, R. (2009) Does Regional Anesthesia Improve Outcome After Total Knee Arthroplasty? Clinical Orthopaedics and Related Research. 467, 2379-2402.

36. Ker, K., Edwards, P., Perel, P., Shakur, H., \& Roberts, R. (2012). Effect of Tranexamic acid on surgical bleeding: systematic review and cumulative metaanalysis. British Medical Journal. 344(e3054), 1-13.

37. Yang, Z., Chen, W., \& Wu, L. (2012). Effectiveness and Safety of Tranexamic Acid in Reducing Blood Loss in Total Knee Arthroplasty: A Meta-Analysis. The Journal of Bone and Joint Surgery. 94-A(13), 1153-1159.

38. Tan, J., Chen, H., Liu, Q., Chen, C., Huang, W. (2013). A meta-analysis of the effectiveness and safety of using Tranexamic acid in primary unilateral total knee arthroplasty. Journal of Surgical Research. 184, 880-887.

39. Soni, A., Saini, R., Gulati, A., Paul, Rajesh, Bhatty, S., \& Rajoli, S.R. (2014) Comparison between intravenous and intra-articular regimens of Tranexamic acid in reducing blood loss during total knee arthroplasty. The Journal of Arthroplasty. $29,1525-1527$
40. Alshryda, S., Mason, J., Vaghela, M., Sarda, P., Nargol, A., Maheswaran, S., Tulloch, C., Anand, S., Logishetty, R., Stothart, B., \& Hungin, A.P.S. (2013). TopicaTranexamic Acid Reduces Blood Los and Transfusion Rates Following Total Knee Replacement: A Randomized Controlled Trial (TRANX-K). The Journal of Bone and Joint Surgery. 95, 1961-1968.

41. Gomez-Barrena,E., Ortega-Andreu, M., Padilla-Eguiluz, N., Perez-Chrzanowska, H., \& Figueredo-Zalve, R. (2014). Topical Intra-articular compared with intravenous tranexamic acid to reduce blood loss in primary total knee replacement: A double-blind, Randomized, Controlled, Noninferiority Clinical Trial. The Journal of Bone and Joint Surgery. 96, 1937-1944

42. Lin, S.Y., Chen, C.H., Fu, Y.C., Huang, P.J., Chang, J.K., \& Huang, H.T. The efficacy of combined use of intraarticular and intravenous tranexamic Acid on reducing blood loss and transfusion rate in total knee arthroplasty. The Journal of Arthroplasty. 30(5), 776-780.

43. Harvey, I.A., Barry, K., Kirby, S.P.J., Johnson, R., \& Elloy, M.A. (1993). Factors Affecting the Range of Movement of Total Knee Arthroplasty. The Journal of Bone and Joint Surgery. 75-B (6), 950-955.

44. Erbert, J.R., Munsie, C., \& Joss, B (2014). Guidelines for the Early Restoration of Active Knee Flexion After Total Knee Arthroplasty: Implications for Rehabilitation and Early Intervention. Archives of Physical Medicine and Rehabilitation. 95, 1135-1140.

45. Exuzides, A., Colby, C., Goldman, J., \& Waaler. A. (2009, October). Reducing bias in a retrospective case-control study: An application of propensity score matching. Presented at the ISPOR 12th Annual European Congress; Paris, France.

46. Parry, M., Wylde, V., \& Blom, A. (2011). Early death following primary total knee replacement. The Journal of Bone and Joint Surgery. 93-A(10), 953-948.

\section{Tissue Sparing Total Hip Arthroplasty Study Group}

The Joint Implant Surgery and Research Foundation has a long history in the study of THA. It began back in 1971 when Professor Charles O. Bechtol, M.D. established JISRF as a nonprofit scientific and educational foundation.

JISRF continues this study with the formation of a new study group of international surgeons and scientists. Findings will be posted on the foundation's web site at www.jisrf.org.

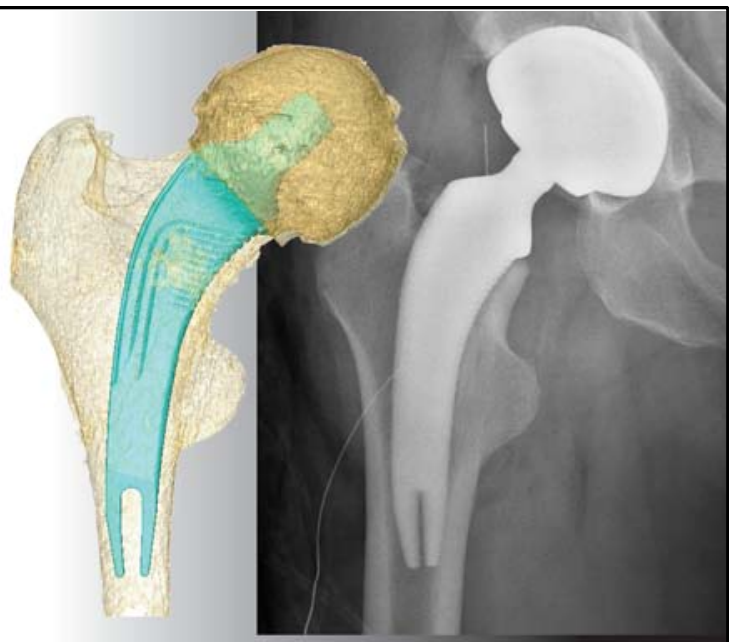

Surgeons interested

in learning more

contact the

Executive Director at www.JISRF.org 